\title{
IMPACTOS EDUCACIONAIS DAS UNIDADES DE POLÍCIA PACIFICADORA: EXPLORANDO EFEITOS SOBRE FLUXOS DOCENTES
}

\author{
Eduardo Ribeiro ${ }^{1}$
}

RESUMO: A partir de 2008, o Governo do Estado do Rio de Janeiro iniciou uma série de intervenções denominadas Unidades de Polícia Pacificadora (UPP). Estas constituem ocupações de territórios previamente dominados por grupos armados organizados, sobretudo pelo tráfico varejista de drogas, com a instalação de batalhões locais; ocupações que, idealmente, seriam seguidas pela implantação de projetos e serviços públicos. As UPPs constituem uma alternativa ao paradigma tradicional da política de enfrentamento ao tráfico varejista de drogas e, embora convivam com o antigo modelo bélico-repressivo, devem provocar, indiretamente, mudanças em diferentes aspectos da vida na cidade. Neste sentido, este trabalho discorrerá sobre os possíveis impactos das UPPs nos resultados educacionais dos territórios atendidos, explorando alterações nos padrões dos fluxos de professores e rotatividade nas escolas públicas municipais.

PALAVRAS-CHAVE: Avaliação de Políticas Públicas; Impactos da Violência; Educação.

Recebido em: outubro de 2012

Aceito em: março de 2013

Para citar este artigo:

RIBEIRO, Eduardo; Impactos educacionais nas Unidades de Polícia Pacificadora: Explorando os efeitos sobre os fluxos docentes. In: Revista Intratextos, 2013, vol 4, no1, p. 27-52. DOI: 10.12957/intratextos.2013.8561

\footnotetext{
${ }^{11}$ Eduardo Ribeiro da Silva é doutorando do Programa de Pós-Graduação em Ciências Sociais da Universidade do Estado do Rio de Janeiro (PPCIS/UERJ) e pesquisador do Laboratório de Análise da Violência (LAV/UERJ). Atualmente é pesquisador visitante na Lancaster University, no âmbito do PDSE/CAPES. Bolsista Capes. Email: eduardoribeirobr@gmail.com
} 


\section{Apresentação e Proposta}

Este trabalho faz parte de uma pesquisa mais ampla, desenvolvida no âmbito de minha tese de doutorado, que discorrerá sobre as relações entre Educação e Violência Urbana no município do Rio de Janeiro. A abordagem proposta consiste em verificar potenciais mudanças nestas relações a partir da análise dos impactos da redução dos conflitos armados e da dominação territorial extralegal, nas localidades em que foram implantadas Unidades de Polícia Pacificadora (UPPs), sobre resultados educacionais e sobre os cotidianos escolares.

O estudo está também inserido em um projeto interinstitucional denominado Observatório Educação e Cidade, que tem como objetivo principal investigar a importância do território (e das segmentações socioterritoriais) em dimensões como equidade e eficácia na escolarização de crianças, adolescentes e jovens (Koslinski et al., 2012)2.

Mais especificamente, este trabalho pretende discorrer sobre os potenciais impactos da Violência Urbana - e das UPPs - nas oportunidades educacionais, observando aspectos relacionados aos movimentos docentes ${ }^{3}$, como transferências entre escolas da rede municipal de ensino e a chegada à escola de professores recém-empossados. A violência é pensada como um efeito dos territórios, um fator exógeno relevante, sobretudo em contextos como o do Rio de Janeiro, para se pensar como certas características dos entornos escolares podem estar direta ou indiretamente associadas ao processo de ensino-aprendizagem, ao trabalho dos educadores e ao desempenho dos alunos.

\section{Configuração da Violência Urbana na Cidade do Rio de Janeiro}

A discussão sobre Violência Urbana assume contornos singulares em uma realidade como a da cidade do Rio de Janeiro. As especificidades de casos como o carioca chegam a tal ponto que não é possível perceber precisamente sua relevância contextual, como efeito de vizinhança que incide direta ou indiretamente sobre os resultados de alunos, educadores e escolas, ou mesmo sobre seus impactos e consequências sobre os diferentes aspectos da vida

\footnotetext{
${ }^{2} \mathrm{O}$ projeto Observatório Educação e Cidade (INEP/CAPES/CNPq) é fruto da colaboração institucional entre o Observatório das Metrópoles (IPPUR/UFRJ), o Laboratório de Avaliação da Educação (Departamento de Educação/PUC-Rio), o Laboratório de Pesquisa em Oportunidades Educacionais (LaPOpE), da faculdade de educação da UFRJ e o Laboratório de Análise da Violência (LAV), vinculado ao Programa de Pós-graduação em Ciências Sociais (PPCIS/UERJ), ao qual este trabalho está mais diretamente vinculado.

${ }^{3}$ Impactos sobre resultados escolares, a vida dos alunos e outros aspectos do cotidiano das escolas serão tratados na tese de doutorado, bem como em trabalhos posteriores.
} 
da cidade, sem que se dimensione a magnitude e o alcance deste fenômeno ou que sejam compreendidos minimamente os mecanismos associados à gênese desta violência, e que tornam o território uma dimensão tão fundamental.

Neste contexto, falar sobre violência passa, sobretudo, por lidar com todo um complexo de relações de interdependência historicamente estabelecidas entre atores sociais legais e extralegais, cujo resultado perverso consiste em um conjunto de práticas conflituosas e interações violentas que resultam em medo, vitimização e, principalmente, em um elevado número de vítimas fatais. Um dos principais diferenciais do contexto carioca, como também de outras cidades brasileiras e da América Latina, é justamente o altíssimo nível de letalidade.

Este elevado número de mortes não se distribui de modo uniforme em toda a população ou entre todas as áreas da cidade, de modo que existem grupos de vítimas preferenciais, para os quais os riscos de vitimização são maiores, e regiões específicas da cidade que concentram um grande número de mortes. Gênero, perfil racial e ciclos de vida são traços sociodemográficos que implicam em probabilidades maiores de vitimização, inclusive com efeitos interativos entre si que potencializam os riscos. Homens, negros e jovens são as maiores vítimas de homicídio, e embora estes sejam elementos universalmente encontrados na literatura, cabe frisar que o diferencial carioca se dá não só pela magnitude, mas também pela desigualdade e distância entre grupos mais e menos atingidos (Cano e Ribeiro, 2007).

Outro aspecto bastante característico do perfil dos contextos de vitimização carioca diz respeito à ampla utilização de armas de fogo. Estas constituem o principal instrumento utilizado nos assassinatos e responderam, na última década, por aproximadamente $84 \%$ de todos os homicídios cometidos na cidade, o que implica em um risco cinco vezes superior ao das mortes por todos os outros meios utilizados. Esta ampla disponibilidade de armas de fogo e também a regularidade da ocorrência de conflitos armados na cidade, conjugadas com a seletividade supramencionada, fazem com que a vitimização letal represente um dos aspectos mais cruéis da desigualdade brasileira, fluminense e carioca.

Vale ainda destacar o caráter acentuadamente territorial da Violência Urbana no Rio de Janeiro. Em conformidade com um modelo de segregação social e residencial carioca, que conjuga o tradicional formato núcleo-periferia, traduzido na distância das periferias nas zonas Norte e Oeste em relação ao centro socioeconômico e cultural da cidade, com dinâmicas de 
microssegregação, fomentadas pela proximidade entre favelas e regiões mais abastadas (Ribeiro \& Koslinski, 2010), a distribuição da violência apresenta taxas mais elevadas nas regiões periféricas e suburbanas da cidade (zonas Norte e Oeste), e também taxas mais elevadas para as favelas, em relação a áreas com outras formas de ocupação habitacional.

Tais peculiaridades, em termos da concentração de conflitos armados e dos homicídios em determinadas localidades, respondem à própria configuração espacial da pobreza, das carências habitacionais e culturais, e do abandono do Estado, remetendo ainda às formas específicas com que determinados grupos criminosos desempenham e reproduzem suas atividades ilegais, justamente nestes territórios desamparados. Em última análise, estes conglomerados de vitimização letal encontrados na cidade são expressões espaciais destas dinâmicas de apropriação e domínio ilegítimo destes espaços não inseridos na cidade formal.

Para compreender os mecanismos relacionados à reprodução da violência letal no Rio de Janeiro, é necessário observar um quadro marcado pela presença destes grupos ilegais e extralegais, armados e relativamente organizados, cuja configuração das atividades criminosas precisa do domínio dos territórios em que atuam. O fato de estes grupos serem fortemente territorializados implica em formas de controle social, diretas e indiretas, sobre pessoas, relações de poder e recursos, e também na sujeição das populações à violência cotidiana e reiterada de conflitos mais ou menos regulares, entre facções rivais ou envolvendo a polícia.

São três os principais atores envolvidos nos conflitos e interações violentas associadas aos homicídios na cidade do Rio de Janeiro: os grupos e facções do tráfico varejista de drogas, as milícias e a própria polícia. Esta última atua tanto como instrumento histórico de uma política de repressão violenta e belicista, como através das relações de cumplicidade, não menos históricas, que alguns de seus membros estabelecem com o crime. O tráfico de drogas assumiu a centralidade da atenção pública em meados dos anos 1980 (Misse, 2003), embora sua presença nas favelas e periferias da cidade seja muito mais antiga. Os grupos milicianos, por sua vez, tornaram-se importantes no cenário da segurança pública carioca apenas na última década, com a intensificação de suas atividades e a expansão sobre territórios antes dominados por traficantes (Alves, 2008; Cano \& Ioot, 2008).

A defesa dos pontos ou locais de venda constitui um dos pontos mais importantes da comercialização da droga na configuração assumida pelo varejo do tráfico de drogas carioca. Por sua vez, as disputas por estes pontos configuram um dos principais vetores dos elevados 
índices de letalidade, principalmente nos locais mais lucrativos, onde há uma maior ameaça de invasão por facções rivais ou mesmo grupos concorrentes dentro de uma mesma facção. Esta defesa do território requer estruturas organizacionais mais elaboradas, o aumento do uso de armas pesadas e um maior controle social do território (Dowdney, 2003; Leeds, 2006).

Este domínio territorial se apresenta tanto em práticas de controle físico direto, através da presença constantemente armada de agentes do tráfico nos interior das comunidades e por códigos de conduta impostos pela força aos moradores, como em práticas associadas ao que Dowdney (2003) chamou de reciprocidade forçada. As facções receberiam dos moradores proteção contra incursões policiais e de facções rivais em troca de favores dos traficantes, principalmente econômicos e da provisão de serviços que o Estado sistematicamente negligenciou a essas populações.

$\mathrm{Na}$ prática, as relações entre traficantes e moradores dos territórios são muito mais amplas e, depois de décadas de convivência, constituem-se, como ressalta Mafra (2006), como interações confusas que expressam relações complexas de favor e contrafavor, presentes em sistemas diretos e indiretos de reciprocidade. Assim, tais relações ultrapassam o âmbito das trocas utilitárias, da dependência econômica e câmbio de serviços, e perpassam redes de amizade, vizinhança e parentesco. Os moradores destas favelas, mesmo não envolvidos com as dinâmicas do tráfico, além de conviverem cotidianamente com a violência e a arbitrariedade, precisam dominar os códigos e valores estabelecidos por estes poderes, que regem a conduta nestes espaços. O domínio do tráfico se dá, portanto, inclusive no campo simbólico, e impõe adesão e reconhecimento de suas hierarquias (Mafra, 2006).

As milícias constituem um ator social com ascensão relativamente recente no cenário da segurança pública fluminense, embora grupos armados com formas de atuação similares, como grupos de extermínio ou polícia mineira, já existissem há muitos anos. O fenômeno ganhou notoriedade a partir de 2006, quando estes grupos, compostos em sua maioria por policiais, começaram a tomar territórios dominados pelos traficantes (Cano \& Ioot, 2008).

Um ponto de contato entre a dominação das milícias e a dos traficantes está na relevância que o controle territorial tem também para estes grupos. De fato, como ressaltam Silva et al. (2008), a exploração econômica dos territórios dominados configura umas das características mais fundamentais dos grupos milicianos. Embora os graus de controle social e interferência no cotidiano dos moradores variem bastante, o caráter coativo da atuação 
destes grupos é uma constante e, como apontam Cano \& Ioot (2008), as milícias mantêm nas localidades dominadas os eixos da dominação exercida pelo tráfico: controle das populações residentes pela intimidação e pelo uso a força. Ameaças, agressões, expulsões e execuções são opções para quem transgride as regras impostas por estes grupos, como nas áreas do tráfico.

A atuação da Polícia e as políticas de segurança historicamente adotadas possuem também papel relevante na reprodução da Violência Urbana. As políticas de segurança têm priorizado ações pontuais militarizadas, de confronto armado, que mobilizam grandes contingentes policiais para invadir e ocupar temporariamente os territórios com uma violência igual ou, muitas vezes, superior à empregada pelos traficantes de drogas. Esta política de confronto é responsável pelo grande número de civis (criminosos e não criminosos) mortos pela ação da polícia, de modo que a ação policial, que além das mortes em confronto inclui execuções sumárias, representa uma parcela considerável dos homicídios ocorridos.

Além da participação nos confrontos armados e da letalidade característica de suas ações de repressão, os altos níveis de corrupção e o envolvimento (ou associação) de alguns setores policiais com o mundo do crime constituem uma parcela importante dos problemas de segurança na cidade (Alves, 2008).

Os efeitos do domínio dos grupos armados, dos confrontos e incursões policiais, e dos altos níveis de violência são muitos, passando pela interrupção de serviços já providos de modo escasso pelo estado, e também por entraves na vida política e comunitária, na medida em que inibem a participação e a independência das organizações e instituições locais. Há ainda efeitos mais diretos sobre estilos de vida e sobre as atividades cotidianamente desenvolvidas pelos moradores destas localidades, provocados pela exposição continuada ao arbítrio dos grupos armados e aos conflitos contra facções rivais ou contra a polícia.

No plano subjetivo, as representações sociais mais gerais apresentam a favela como o lócus central da violência na cidade, embora existam outras áreas com situação socioeconômica e violência similares (Cano et al., 2004). Desta forma, as favelas possuem, em relação a outras áreas da cidade formal, além de uma série de distâncias sociais, compartilhadas por outros territórios periféricos, outras tantas distâncias simbólicas, sendo representadas como territórios estigmatizados e associados à violência e à reprodução do crime. Estas diferenças tenderiam a se acentuar nas regiões mais abastadas, em que as 
desigualdades (entre favela e não favela) se tornam mais evidentes e onde a microssegregação residencial e seus processos são mais visíveis e demarcados (Ribeiro \& Koslinski, 2010).

\section{Implementação, impactos das UPPs}

A partir de novembro de 2008, o Governo do Estado do Rio de Janeiro iniciou uma série de intervenções denominadas Unidades de Polícia Pacificadoras (UPP). Estas configuram ocupações permanentes em territórios anteriormente dominados por grupos armados organizados ${ }^{4}$, com a instalação local de batalhões de polícia seguida, idealmente, pela implantação de projetos sociais e pela provisão de serviços públicos. Até então foram instaladas 28 unidades $^{5}$, todas na cidade do Rio de Janeiro.

A instalação das UPPs conjuga ações policiais de repressão e prevenção da violência e da criminalidade que podem ser dispostas em quatro etapas, denominadas fases da pacificação ${ }^{6}$. A primeira etapa é denominada intervenção tática, e implica na retomada dos territórios dominados pelos grupos armados organizados. Esta ocorre com intervenções repressivas amplas, com um número grande de policiais civis e, sobretudo, militares, com a ação de batalhões especializados, principalmente o $\operatorname{BOPE}^{7}$ e, algumas vezes, com a participação de agentes da Polícia Federal ou integrantes das Forças Armadas.

Uma diferença importante destas operações em relação às intervenções policiais historicamente realizadas, e que ainda são comuns nas localidades não atendidas pelas UPPs, diz respeito à publicização prévia das invasões, denominada guerra avisada. Esta medida permite que os grupos armados estabelecidos se desmobilizem e abandonem os territórios, o que preserva a segurança dos moradores das comunidades e dos próprios policiais. Por outro lado, ocorreram críticas pelo fato destas incursões renderem poucas prisões, o que poderia resultar no deslocamento das dinâmicas criminosas para outras regiões da cidade ou do estado. Em todo caso, chegaram a existir conflitos entre policiais e traficantes, sobretudo

\footnotetext{
${ }^{4}$ Este termo se refere aqui basicamente aos grupos que operam o comércio varejista de drogas ilícitas, na medida em que apenas uma única unidade das 28 foi instalada em território anteriormente dominado por milicianos. A expressão foi utilizada originalmente por Dowdney (2003).

${ }^{5} \mathrm{O}$ presente artigo foi redigido em outubro de 2012.

${ }^{6} \mathrm{O}$ termo fases da pacificação é uma categoria nativa utilizada por gestores e policiais para fazer referência às etapas de implantação das UPPs. O termo pacificação em si já é bastante controverso no sentido que, por exemplo, denota que o quadro simbólico de referência ainda não se alterou (Silva, 2010). A expressão pacificação foi utilizada neste artigo apenas como referência ao projeto das UPPs.

${ }^{7}$ Batalhão de Operações Policiais Especiais da Polícia Militar.
} 
durante a instalação das primeiras unidades, mas o mais comum, principalmente depois que esta medida foi tomada, foram ocupações relativamente tranquilas.

À retomada se segue a consolidação do domínio policial sobre os territórios, etapa denominada estabilização e, posteriormente, a implantação física da UPP, com comando local e efetivo específico formado em sua maioria por policiais que ingressaram recentemente na corporação, justamente para integrar estas unidades ${ }^{8}$. O efetivo lotado nas UPPs varia entre 100 e pouco mais de 300 policiais, o que resulta em um número de policiais por habitante muito superior à média registrada no estado (Cano, Borges \& Ribeiro, 2012), e indica um modelo de policiamento com uma forte componente de saturação do contingente policial.

A fase final e, até o momento, menos sistematizada e definida, constitui a chamada pós-ocupação. Nesta, garantido o controle territorial e organizadas as atividades de patrulhamento na comunidade', entrariam em cena políticas públicas, regularização de serviços urbanos e programas sociais, além do monitoramento do projeto. Nota-se, neste caso, um processo no qual a intervenção governamental transita de um pólo que se inicia com uma forte atuação policial, de forma predominantemente repressiva, para um pólo contrário em que as ações preventivas (inclusive por parte da polícia) assumiriam um peso maior.

Este tem sido um dos grandes desafios da política, na medida em que as localidades "pacificadas" apresentam carências sociais e econômicas que além de inúmeras e historicamente constituídas, tendem a aumentar. O acesso a direitos sempre implica em demandas por outros direitos, e o Estado precisa estar preparado para suprir as demandas destes territórios abandonados por muito tempo, teoricamente reincorporados pela polícia e que, na prática, ainda precisam ser integrados socialmente à cidade formal.

A falta de confiança, não apenas em relação às polícias, mas aos governos, constitui um sentimento que se fortalece também por conta do receio de muitos moradores de que esta seja mais uma intervenção pública temporária. A recuperação da legitimidade da Polícia (e do Estado) junto a estes moradores não é tarefa fácil e embora o projeto apresente, de modo

\footnotetext{
${ }^{8}$ Esta medida pretende evitar práticas e posturas recorrentes da atividade policial no Estado do Rio de Janeiro, o que, tanto policiais quanto gestores, classificam como vícios de rua. Reflete ainda a tentativa de restabelecer a confiança e a legitimidade da PM, com o estabelecimento de uma nova relação com as comunidades historicamente vitimadas pela violência das incursões policiais e pelas constantes violações cometidas.

${ }^{9}$ As atividades de policiamento nas áreas pacificadas podem não ser necessariamente classificadas como atividades de policiamento comunitário, sobretudo se discutidas, sob o registro das características operacionais elencadas por Skolnick \& Bailey (2002), para pensar conceitualmente esta modalidade de policiamento.
} 
geral, avaliação positiva por parte destes moradores, a desconfiança ainda assume níveis elevados (IBPS, 2010).

Os impactos mais importantes da instalação das UPPs são, por um lado, a redução dos conflitos e disputas armadas por pontos de venda e a redução das incursões e operações policiais, substituídas por rondas e trabalho preventivo. Isto implica na diminuição da violência letal (do número de mortes evitáveis) e dos crimes perpetrados com armas de fogo (Cano, Ribeiro e Borges, 2012). Por outro lado, há a interrupção do controle ostensivo dos territórios pelos grupos armados ilegais, que se caracterizava não apenas o uso da brutalidade e da força física, mas também pela regulamentação de regras sociais e de convivência locais.

A retomada dos territórios, ao interromper estados de violência ${ }^{\mathbf{1 0}}$ sob os quais viviam estas comunidades, restabelece possibilidades de integração e participação, e permite a chegada de outras políticas e serviços públicos. Sob este registro - dos efeitos da redução da violência sobre: (a) instituições, serviços e políticas que atuam nos territórios; (b) dinâmicas comunitárias locais e; (c) trajetórias individuais e coletivas nas localidades antes dominadas pelos grupos armados - é que se supõem os potenciais impactos sociais das UPPs.

As UPPs constituem, portanto, uma política pública especificamente orientada para o campo da segurança, mas com impactos que podem se estender a processos, políticas e serviços relativos a outros setores. Estes potenciais efeitos sociais indiretos e não previstos merecem ser avaliados. No que tange ao campo educacional é necessário perceber que a Violência Urbana, enquanto fenômeno territorialmente presente no entorno de algumas das escolas, incidiria tanto sobre o cotidiano das atividades escolares quanto sobre trajetórias individuais dos alunos, funcionários e professores, atuando nas relações sociais e contextos de interação circunscritos nos lugares de moradia e ambientes de trabalho. Deve-se ressaltar que este efeito de vizinhança tão peculiar à realidade carioca, a violência no entorno das escolas, pode ser objetiva e subjetivamente influenciado pela presença das UPPs nos territórios.

\section{Impactos da violência na vizinhança da Escola}

Este estudo parte da hipótese de que a Violência Urbana, delineada nos termos das seções anteriores, limita oportunidades educacionais, interferindo negativamente nos

${ }^{10}$ Ver Michaud (1989). 
resultados dos alunos e no cotidiano da escola. Espera-se que alunos, funcionários e professores de escolas situadas em territórios com maior violência, e aqueles que residem em locais mais violentos, apresentem, em média, piores resultados educacionais.

A mesma lógica pode ser aplicada às instituições: escolas situadas em áreas conflagradas enfrentariam uma série de dificuldades que estariam ausentes nos territórios mais calmos e poderiam apresentar, em média, piores condições de estudo e trabalho, bem como piores resultados agregados.

Considerando as especificidades do panorama da segurança pública do Rio de Janeiro, que incluem o domínio territorial das áreas mais pobres por grupos ilegais e extralegais, e conflitos mais ou menos frequentes destes grupos entre si e contra a polícia, é possível antecipar uma multiplicidade de formas através das quais as escolas poderiam ser afetadas. Tais efeitos ocorreriam em diferentes níveis, podendo atuar sobre alunos, professores e turmas, e sobre as instituições de ensino.

Nos territórios conflagrados, em decorrência dos conflitos, o comércio, o expediente de instituições públicas e as atividades cotidianas das pessoas, são esporadicamente interrompidos. Não são raros relatos de escolas que fecham suas portas ou de alunos que não chegam à escola por residirem em áreas em que ocorrem tiroteios. Mesmo quando cessam os conflitos, o medo e a insegurança permanecem com a possibilidade de novos confrontos.

A lógica das facções e dos demais grupos criminosos opera mesmo sobre os moradores sem qualquer envolvimento. A afiliação e o pertencimento são compulsoriamente estabelecidos a partir da presença no território. O mesmo ocorre com instituições presentes nestes territórios e com as pessoas que destas fazem parte. Nas escolas localizadas em espaços dominados por grupos armados, principalmente nas áreas de favela e adjacências, é extremante difícil exercer as atividades cotidianas sem que, em alguma medida, se considere o domínio e a influência destes poderes ilegais que, dependendo da localidade podem ter posturas bem diferentes, no que tange às relações e tensões estabelecidas com a escola, com diretores, professores e alunos.

Em alguns casos as escolas conseguem se manter relativamente alheias e independentes do domínio político e simbólico destes grupos criminosos. Outras vezes, a manutenção desta distância não é possível, e se estabelecem relações de negociação, sujeição 
ou mesmo resistência, por parte de diretores e professores. Toda a discussão sobre a autonomia da instituição escolar precisa ser contextualizada, sob esta perspectiva.

Diretores, professores e alunos precisam ao menos respeitar os códigos, hierarquias e valores dos territórios em que atuam, conhecendo quais condutas são aprovadas e reprovadas, ou dominando a leitura dos contextos e circunstâncias que se apresentam. Nos casos mais graves, a violência externa passa a fazer parte do cotidiano da escola, até mesmo com a venda de drogas ou a presença de indivíduos armados nos espaços internos ou circundantes da escola. Tanto nos contextos mais graves quanto nos menos graves, as aulas podem ser interrompidas por determinação dos grupos criminosos. Nestes casos, o território incide diretamente sobre a oferta e sobre a qualidade dos serviços prestados pelas escolas.

A dominação dos grupos armados organizados nos territórios ocupados ultrapassa o uso da coação e da força, e assume aspectos mais sutis relacionados à atribuição de identidades, e interiorização de lógicas e práticas próprias a estes grupos, com considerável peso de referências simbólicas, demarcação de fronteiras e definição de rivalidades (Silva et $a l ., 2008)$. Isto pode ser claramente notado nas rusgas existentes entre jovens moradores de favelas e bairros dominados por facções rivais do tráfico de drogas, que se dão, em muitos casos, mesmo para indivíduos que não possuem envolvimento efetivo com os grupos.

De fato, muitas gerações de jovens cresceram e foram socializadas sob a influência dos códigos e práticas estabelecidos por estes grupos armados organizados, sobretudo do tráfico de drogas. No ambiente escolar estes códigos entram em conflito com valores e condutas esperados pelos professores, e se traduzem em indisciplina e no não reconhecimento da autoridade e das hierarquias escolares.

Todos estes elementos, por sua vez, condicionam as expectativas dos professores em relação aos alunos que residem nestes territórios, bem como sua percepção sobre a capacidade e sobre as possibilidades de futuro destes alunos (Paiva \& Burgos, 2009; Ribeiro \& Koslinski, 2010). Se por um lado os professores, muitas vezes, operam com uma lógica que criminaliza e estigmatiza os alunos provenientes dos territórios favelados, por outro lado, muitos professores se sentem inseguros nas salas aula.

Uma consequência prática dos conflitos e da violência é que nas escolas das áreas mais perigosas e instáveis, onde os tiroteios são mais comuns e a insegurança é maior, ocorre 
uma perda de prestígio por parte da instituição escolar e, por conseguinte, a redução de sua capacidade de atrair e reter alunos e também professores, diretores e outros funcionários. Pode haver estigmatização das escolas das áreas conflagradas (Penha e Figueiredo, 2009).

A própria interrupção regular das atividades das escolas, em decorrência dos conflitos armados ou pelas ordens dos grupos ilegais, não apenas compromete a autonomia escolar, como também gera um estigma de escola ruim, ou de pior qualidade, que atinge igualmente seus professores e alunos. A quebra da estabilidade necessária para o funcionamento da escola, que se traduz em uma menor capacidade de organização administrativa e pedagógica, é percebida tanto dentro quanto fora do ambiente escolar e alimenta representações sociais que fragilizam ainda mais a situação destas escolas.

Decorrentes da insegurança objetiva e subjetivamente percebida, estas escolas que atendem às áreas violentas perderiam muitos professores (por transferência, desligamento ou pedidos de licença), e teriam maior dificuldade de recrutar bons profissionais. Dos profissionais que assumem estes postos de trabalhos, muitos não teriam a intenção de permanecer nestas escolas e tentariam rapidamente se transferir para outras escolas. Em suma os territórios mais violentos poderiam sofrer mais intensamente problemas relacionados à qualidade de seu corpo docente e à disponibilidade de professores, na medida em que constituem lugares menos atrativos e com piores condições de trabalho (Cano, 2005; Carreira e Carneiro, 2008; Penha e Figueiredo, 2009).

\section{Desenhos avaliativos}

Uma pesquisa avaliativa que pretende observar o impacto de determinada política ou projeto é um tipo peculiar de pesquisa causal, na qual se pretende verificar se esta intervenção foi ou não responsável pelas alterações verificadas após sua execução. Procura-se estabelecer uma relação de causa e efeito entre a intervenção e seus potenciais resultados, descartando todas as possíveis outras variáveis que poderiam provocar o mesmo impacto no fenômeno de interesse, e considerando hipóteses alternativas para sua variação, como hipóteses de substituição e deslocamento geográfico (Cano, 2002; 2005; Shadish et al., 2002). 
No que tange às políticas e programas sociais é comum que nem todos os quesitos necessários à lógica da pesquisa experimental possam ser cumpridos ${ }^{11}$. Os desenhos avaliativos que seguem esta lógica experimental, mas descumprem alguma de suas prerrogativas, são denominados: quase-experimentos.

O fato de a violência e seus impactos constituírem fenômenos sociais complexos, influenciando (e sendo influenciados por) um grande número de fatores, torna complicada a tarefa de identificar e descartar hipóteses alternativas para as relações a serem testadas, enfraquecendo a validade das inferências causais. Soares (2007) afirma que, diante da impossibilidade de se isolar o campo de intervenção das políticas e performances a serem examinadas, é necessário ter cautela na simples aplicação da cláusula ceateris-paribus.

Se por um lado elevam-se as preocupações com a consecução de desenhos avaliativos mais robustos, atentos às ameaças à validade e confiabilidade dos resultados e às especificidades dos fenômenos, por outro lado, no que tange aos impactos da violência sobre as oportunidades educacionais, não seria tecnicamente possível e, muito menos, eticamente viável controlar níveis de variação da causa (violência e vitimização) para acompanhar as alterações dos resultados escolares ocorridas nos territórios pesquisados.

Neste contexto de negociação entre o metodologicamente ideal e o viável, a implantação das UPPs constitui uma oportunidade privilegiada para o estudo da relação entre violência e resultados escolares, na medida em que esta intervenção provocaria reduções bruscas, pontuais e continuadas na violência no entorno de determinadas escolas. A instalação de uma UPP consiste em um evento bem localizado no tempo e no espaço, a partir do qual ocorre, ou espera-se que ocorra, uma alteração abrupta na evolução e no comportamento de determinados fenômenos, mudando o nível ou a tendência de séries históricas. Este efeito remete aos que economistas denominam choques. Por conta da redução que opera nos níveis de vitimização as UPPs devem alterar drasticamente um conjunto amplo de variáveis sociais, possibilitando explorar justamente as associações que existiam entre estas variáveis e a violência.

${ }^{11}$ Controle da introdução da causa (intervenção ou política) pelo pesquisador; existência de grupos de comparação (experimental e de controle) equivalentes nas dimensões relevantes ou, preferencialmente, aleatorizados; controle de todas as variáveis externas ou intervenientes, que possam estar associadas aos efeitos mensurados e, em particular, daquelas variáveis que estejam associadas concomitantemente com a intervenção implementada e seu impacto esperado (Cano, 2005). 
Por outro lado, o fato desta redução na violência não ser ampla, mas pontual, no sentido de que abrange apenas as escolas nas áreas das UPPs, possibilita estabelecer grupos de comparação, passíveis de serem utilizados para avaliar em paralelo a evolução de determinados fenômenos de interesse no mesmo período, em localidades com e sem a intervenção. Esta possibilidade remete metodologicamente à noção de experimento natural ${ }^{12}$, na medida em que a própria forma como é executada a política permite um maior controle da situação experimental, do contexto em que é realizada a pesquisa. Assim, dado que não é possível instalar simultaneamente unidades em todas as localidades que precisariam ser alvo desta política, escolas em territórios com contextos sociais semelhantes, mas que não receberam o projeto representariam bons grupos de controle, passíveis de serem utilizados na avaliação destes impactos.

O desenho avaliativo precisa, portanto, acompanhar a evolução de determinados indicadores, tendo como unidade de análise a escola. As comparações a serem realizadas passam por observar escolas localizadas em territórios atualmente dominados por grupos armados organizados (grupo de controle), em contraposição a escolas em áreas anteriormente dominadas, mas atualmente sob intervenção. As escolas nas áreas em que o programa não foi implantado (ou áreas com UPPs instauradas posteriormente) compõem grupos de comparação válidos, desde que a similaridade entre as áreas que compõem ambos os grupos seja respeitada. Cano $(2002 ; 2005)$ aponta a necessidade de um cuidado especial a ser despendido na busca por territórios similares para a composição dos grupos, na impossibilidade da utilização de critérios aleatórios de atribuição.

Tomando como base o texto de Campbell \& Stanley (1963), o desenho avaliativo utilizado foi o de Séries Temporais Múltiplas, que consegue evitar os efeitos de grande parte das ameaças à Validade Interna ${ }^{13} \mathrm{e}$, em alguns casos podem alcançar uma Validade Interna para a inferência causal tão forte quanto a dos estudos experimentais. Desta forma, busca-se analisar a evolução de variáveis escolares, antes e depois da implantação de cada UPP, segundo o seguinte desenho:

$$
\begin{array}{llllllll}
\mathrm{O}_{1} & \mathrm{O}_{2} & \mathrm{O}_{3} & \mathrm{O}_{4} & \mathrm{X} & \mathrm{O}_{5} & \mathrm{O}_{6} & \mathrm{O}_{7}
\end{array}
$$

\footnotetext{
${ }^{12}$ Ver Shadish et al. (2002) e Cano (2002).

${ }^{13}$ Segundo Campbell \& Stanley (1963), a Validade Interna se refere ao grau de certeza que o pesquisador possui de que foi de fato a intervenção que provocou o efeito significativamente observado, e não uma terceira variável ou hipótese concorrente.
} 


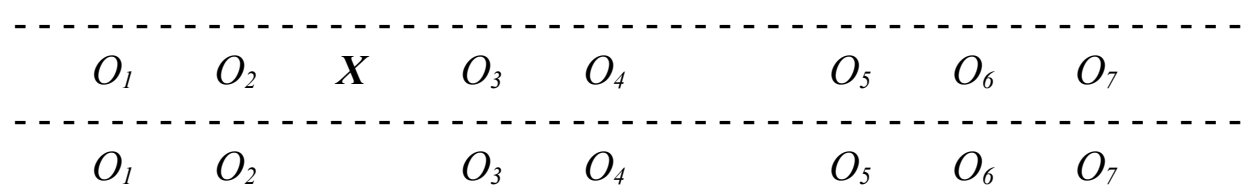

Como apontam Campbell \& Stanley (1963), este esquema é caracterizado pela coleta de mensurações sucessivas $\left(O_{1}, O_{2}, \ldots, O_{7}\right)$, antes e depois do momento da intervenção $(X)$, contando assim com várias medidas para o pré-teste e para o pós-teste. Estas múltiplas medidas de pré-teste possibilitam o estabelecimento de uma linha-base, cuja extrapolação a partir do momento da intervenção deve ser contraposta com os resultados observados nos póstestes. O que se procura, neste caso são diferenças significativas no nível da série ou em seu coeficiente angular, que ocorram entre os pontos $\mathrm{O}_{4}$ e $\mathrm{O}_{5}$ (na primeira linha) ou $\mathrm{O}_{2}$ e $\mathrm{O}_{3}$ (na segunda linha). A análise da série histórica permite identificar tendências, ciclos e sazonalidade que possam interferir na estimação dos resultados.

Por sua vez, a existência de séries paralelas, sem a ocorrência de uma UPP, atua como grupo de controle não equivalente, contra o qual os resultados das áreas com UPP devem ser comparados. Esta estratégia permite afastar em parte os chamados efeitos de História (Campbell \& Stanley, 1963; Cano, 2002), na medida em que permitem comparar, exatamente no momento da intervenção, movimentos mais gerais da evolução do fenômeno na cidade e nas regiões da cidade. Movimentos ou tendências que poderiam ser confundidos com impactos da UPP e que, portanto, precisam ser descontados nas análises. Mesmo as escolas em áreas de UPP, em momentos anteriores à intervenção, servem como grupos de controle.

Neste estudo, foi avaliado o impacto das UPPs sobre a capacidade das escolas de manter seu corpo docente, bem como de atrair novos quadros. Para tanto, a partir de dados sobre movimentos docentes, registros administrativos cedidos pela Secretaria Municipal de Educação (SME), no âmbito do projeto Observatório Educação e Cidade, foram geradas três medidas relacionadas à rotatividade docente nas escolas municipais, sejam elas: a) o número de professores recém-empossados que chegam às escolas; b) o número de professores que chegam às escolas, transferidos de outras unidades da rede municipal e; c) o número de professores que deixam as escolas e se transferem para outras escolas da rede municipal.

\section{Resultados exploratórios}


Foi elaborada uma base de dados contendo as variações mensais dos três indicadores propostos (número de professores recém-empossados; professores que chegam transferidos de outras unidades; e que se transferem para outras escolas), para as instituições municipais de ensino, entre os anos de 2006 e 2011. Estavam presentes na amostra 1.314 unidades escolares, sendo 960 escolas (73\%), 253 creches (19,3\%) e 101 CIEPs (7,7\%). Cada unidade contou com 72 registros mensais para cada indicador de movimentação docente.

Além dos três indicadores supracitados (variáveis dependentes), a variável de maior interesse era justamente aquela que registrava a presença ou ausência das UPPs nos territórios ${ }^{14}$. Para obter estas informações foram utilizadas técnicas de geoprocessamento, a partir das quais os endereços das escolas foram sobrepostos às circunscrições das UPPs, cedidas pela Coordenadoria de Polícia Pacificadora (CPP). Deste modo foi criado um indicador espacial que apontava três situações: a) unidades educacionais dentro das circunscrições das UPPs; b) unidades fora das circunscrições, mas localizadas até 250 metros da circunscrição de UPP mais próxima; c) unidades educacionais com distância superior a 250 metros de qualquer uma das UPPs. O objetivo desta gradação foi avaliar efeitos indiretos das UPPs sobre as escolas e controlar hipóteses de deslocamento territorial da violência.

Para cada uma das três variáveis dependentes foram ajustados modelos mistos generalizados de regressão (Generalized linear mixed models - GLMM), com distribuição Poisson, próprios para análises longitudinais de dados provenientes de contagens, considerando dois desenhos avaliativos. No primeiro, todas as unidades escolares disponíveis estavam presentes na amostra, o que implica em um grupo de controle com escolas que possuem contextos territoriais bastante diferenciados. O segundo considerou apenas escolas que, a partir de algum momento dentro do período estudado teriam sofrido influências das UPPs. Este último desenho representa um grupo de controle mais específico. As tabelas a seguir trazem as estimativas dos efeitos fixos dos seis modelos finais.

\section{Tabela 1: Modelos Hierárquicos Generalizados de dois níveis para o № mensal de professores recém-empossados nas escolas municipais da Cidade do Rio de Janeiro}

\footnotetext{
${ }^{14}$ Embora atualmente (outubro de 2012) hajam 28 UPPs instaladas, para fins analíticos foram consideradas apenas as unidades implementadas até maio de 2011. De novembro de 2008 até esta data, as seguintes localidades haviam sido contempladas com UPPs: 1) Santa Marta; 2) Cidade de Deus; 3) Batam; 4) Babilônia e Chapéu-Mangueira; 5) Pavão-Pavãozinho e Cantagalo; 6) Tabajaras e Morro dos Cabritos; 7) Providência; 8) Borel; 9) Formiga; 10) Andaraí; 11) Salgueiro; 12) Turano; 13) Macacos; 14) São João, Matriz e Quieto; 15) Coroa, Fallet e Fogueteiro; 16) Escondidinho e Prazeres; 17) São Carlos. A UPP que contemplava Mangueira e Tuiuti não foi considerada por ter sido instaurada no final do ano de 2011.
} 


\begin{tabular}{|c|c|c|c|c|c|c|c|c|}
\hline \multirow[b]{2}{*}{ Variáveis } & \multicolumn{4}{|c|}{ Desenho $1^{\#}$} & \multicolumn{4}{|c|}{ Desenho $2^{\# \#}$} \\
\hline & $\mathrm{B}$ & Sig. & $\mathrm{e}^{\mathrm{B}}$ & $\Delta \%$ & B & Sig. & $\mathrm{e}^{\mathrm{B}}$ & $\Delta \%$ \\
\hline Intercepto & $-7,22$ & $* * *$ & & & $-7,86$ & $* * *$ & & \\
\hline Nível 1: Escola/Mês & \multicolumn{5}{|c|}{92.148 observações } & \multicolumn{3}{|c|}{5.724 observações } \\
\hline Tempo em meses & 0,042 & $* * *$ & 1,043 & $4,3 \%$ & 0,048 & $* * *$ & 1,049 & $4,9 \%$ \\
\hline \multicolumn{9}{|l|}{ Escolas sem proximidade com UPP } \\
\hline Escola a 250 metros de UPP & 0,309 & $* *$ & 1,362 & $36 \%$ & 0,246 & --- & 1,278 & $29 \%$ \\
\hline Escola na circunscrição de UPP & 0,327 & $* * *$ & 1,387 & $39 \%$ & 0,291 & $*$ & 1,337 & $34 \%$ \\
\hline Profs. transferidos (2 meses atrás) & 0,136 & $* * *$ & 1,146 & $15 \%$ & 0,22 & $* * *$ & 1,248 & $25 \%$ \\
\hline Nível 2: Escola & \multicolumn{4}{|c|}{1.314 escolas } & \multicolumn{4}{|c|}{87 escolas } \\
\hline \multicolumn{9}{|c|}{ Escolas sem proximidade com Favela } \\
\hline Escola a 100 metros de Favela & 0,100 & $* *$ & 1,105 & $10,5 \%$ & $-0,062$ & --- & 0,940 & $-6,0 \%$ \\
\hline Escola situada em Favela & 0,151 & $*$ & 1,163 & $16 \%$ & 0,136 & --- & 1,146 & $14,6 \%$ \\
\hline Tamanho da Escola: № de turmas & 0,045 & $* * *$ & 1,047 & $4,7 \%$ & 0,051 & $* * *$ & 1,053 & $5,3 \%$ \\
\hline
\end{tabular}

Variável dependente: $\mathrm{N}^{\mathrm{o}}$ de professores recém-empossados por mês.

--- Não significativo. Significativo com: $\alpha<0,001(* * *) ; \alpha<0,01\left({ }^{* *}\right) ; \alpha<0,05(*) ; \alpha<0,10$ (.)

\# Modelo estimado considerando todas as escolas da cidade do Rio de Janeiro, de 2006 a 2011.

\#\# Modelo estimado considerando apenas as escolas a 250 metros de UPPs ou menos, de 2006 a 2011.

\#\#\# Categorias de referência para análise.

Tabela 2: Modelos Hierárquicos Generalizados de dois níveis para o № mensal de professores que chegam à escola transferidos de outras escolas da rede municipal Desenho $1^{\#} \quad$ Desenho $2^{\# \#}$

\begin{tabular}{|c|c|c|c|c|c|c|c|c|}
\hline Variáveis & $\mathrm{B}$ & Sig. & $\mathrm{e}^{\mathrm{B}}$ & $\Delta \%$ & $\mathrm{~B}$ & Sig. & $\mathrm{e}^{\mathrm{B}}$ & $\Delta \%$ \\
\hline Intercepto & $-1,854$ & $* * *$ & & & $-2,606$ & $* * *$ & & \\
\hline Nível 1: Escola/Mês & \multicolumn{4}{|c|}{92.148 observações } & \multicolumn{4}{|c|}{5.724 observações } \\
\hline Tempo em meses & $-0,001$ & $* * *$ & 0,999 & $-0,1 \%$ & 0,001 & --- & 1.001 & $0,1 \%$ \\
\hline \multicolumn{9}{|l|}{ Escolas sem proximidade com UPP \#\#\# } \\
\hline Escola a 250 metros de UPP & 0,032 & --- & 1,032 & $3,2 \%$ & $-0,081$ & --- & 0,923 & $-8 \%$ \\
\hline Escola na circunscrição de UPP & 0,049 & --- & 1,050 & $5,0 \%$ & $-0,011$ & --- & 0,989 & $-1,1 \%$ \\
\hline Profs. transferidos (2 meses atrás) & 0,485 & $* * *$ & 1,624 & $62,4 \%$ & 0,629 & $* * *$ & 1,876 & $88 \%$ \\
\hline Nível 2: Escola & \multicolumn{4}{|c|}{1.314 escolas } & \multicolumn{4}{|c|}{87 escolas } \\
\hline \multicolumn{9}{|c|}{ Escolas sem proximidade com Favela"\#\# } \\
\hline Escola a 100 metros de Favela & $-0,172$ & $* * *$ & 0,842 & $-15,8 \%$ & 0,094 & --- & 1,099 & $10 \%$ \\
\hline Escola situada em Favela & $-0,531$ & $* * *$ & 0,588 & $-41,2 \%$ & $-0,162$ & --- & 0,850 & $-15 \%$ \\
\hline Tamanho da Escola: № de turmas & 0,029 & $* * *$ & 1,029 & $2,9 \%$ & 0,048 & $* * *$ & 1,049 & $4,9 \%$ \\
\hline
\end{tabular}

Variável dependente: $\mathrm{N}^{\mathrm{o}}$ de professores que chegaram à escola por mês, transferidos de outras escolas da rede municipal. --- Não significativo. Significativo com: $\alpha<0,001(* * *) ; \alpha<0,01(* *) ; \alpha<0,05(*) ; \alpha<0,10$ (.)

\# Modelo estimado considerando todas as escolas da cidade do Rio de Janeiro, de 2006 a 2011.

\#\# Modelo estimado considerando apenas as escolas a 250 metros de UPPs ou menos, de 2006 a 2011.

\#\#\# Categorias de referência para análise.

Tabela 3: Modelos Hierárquicos Generalizados de dois níveis para o № mensal de professores que deixam a escola transferidos para outras escolas da rede municipal

\section{Desenho $1^{\#} \quad$ Desenho $2^{\# \#}$}




\begin{tabular}{|c|c|c|c|c|c|c|c|c|}
\hline Variáveis & $\mathrm{B}$ & Sig. & $e^{B}$ & $\Delta \%$ & $\mathrm{~B}$ & Sig. & $e^{B}$ & $\Delta \%$ \\
\hline Intercepto & $-2,909$ & $* * *$ & & & $-4,231$ & $* * *$ & & \\
\hline Nível 1: Escola/Mês & \multicolumn{4}{|c|}{92.148 observações } & \multicolumn{4}{|c|}{5.724 observações } \\
\hline Tempo em meses & 0,010 & $* * *$ & 1,010 & $1,0 \%$ & 0,017 & $* * *$ & 1,017 & $1,7 \%$ \\
\hline \multicolumn{9}{|l|}{ Escolas sem proximidade com UPP \#\#\# } \\
\hline Escola a 250 metros de UPP & 0,052 & $* *$ & 1,053 & $5,3 \%$ & $-0,179$ & . & 0,836 & $-16 \%$ \\
\hline Escola na circunscrição de UPP & 0,024 & $* * *$ & 1,025 & $2,5 \%$ & $-0,213$ & $*$ & 0,808 & $-19 \%$ \\
\hline Profs. transferidos (2 meses atrás) & 0,082 & $* * *$ & 1,085 & $8,5 \%$ & 0,108 & $* * *$ & 1,114 & $11,4 \%$ \\
\hline Nível 2: Escola & \multicolumn{4}{|c|}{1.314 escolas } & \multicolumn{4}{|c|}{87 escolas } \\
\hline \multicolumn{9}{|c|}{ Escolas sem proximidade com Favela } \\
\hline Escola a 100 metros de Favela & $-0,171$ & $* *$ & 0,842 & $-15 \%$ & 0,005 & -- & 1,005 & $0,5 \%$ \\
\hline Escola situada em Favela & $-0,506$ & $*$ & 0,603 & $-40 \%$ & $-0,204$ & --- & 0,816 & $-18 \%$ \\
\hline Tamanho da Escola: № de turmas & 0,043 & $* * *$ & 1,043 & $4,3 \%$ & 0,077 & $* * *$ & 1,080 & $8,0 \%$ \\
\hline
\end{tabular}

Variável dependente: $\mathrm{N}^{\mathrm{o}}$ de professores que deixaram a escola por mês, transferidos para outras escolas da rede municipal. --- Não significativo. Significativo com: $\alpha<0,001(* * *) ; \alpha<0,01(* *) ; \alpha<0,05$ (*); $\alpha<0,10$ (.)

\# Modelo estimado considerando todas as escolas da cidade do Rio de Janeiro, de 2006 a 2011.

\#\# Modelo estimado considerando apenas as escolas a 250 metros de UPPs ou menos, de 2006 a 2011.

\#\#\# Categorias de referência para análise.

Os modelos estatísticos consideraram além da variável independente, seja ela, a presença de UPPs nos territórios das instituições municipais de ensino, algumas variáveis relacionadas a efeitos temporais (como tendência e dependência serial) e espaciais (como o fato de a escola estar situada perto ou dentro de uma favela). Além disso, o número de turmas foi considerado também como variável de controle, representando o tamanho da escola. Maiores escolas, com um maior número de turmas, professores e alunos, estiveram associadas nas análises dos três indicadores analisados a maiores movimentações docentes.

Para cada uma das unidades educacionais consideradas, a variável tempo registrou os 72 meses para os quais foram coletados dados. O primeiro mês analisado, janeiro de 2006, constitui o tempo zero (o início da série), e os meses seguintes foram representados por um contador discreto que acumula uma unidade por mês até atingir seu valor máximo no mês de dezembro de 2011 (71). Esta variável representa a evolução dos indicadores de movimentação docente com o passar o tempo, e permite controlar tendências lineares nas séries históricas.

Uma tendência significativa de crescimento mensal foi observada no ingresso de novos professores na rede municipal (Tabela 1). Esta foi significativa em ambos os desenhos avaliativos, que apresentaram coeficientes semelhantes, embora o coeficiente no modelo para o segundo desenho avaliativo, cuja amostra é mais seletiva, tenha sido ligeiramente superior. 
Estes resultados apontam um aumento progressivo na admissão de novos professores pelo município, entre os anos de 2006 e 2011, na ordem de 4\% a 5\% mensais, em média.

Neste mesmo período, é interessante notar que, concomitante a esta tendência de crescimento na entrada de novos professores, existe também uma tendência de crescimento do número de professores que deixam as escolas, transferindo-se para outras escolas (Tabela 3). Tal tendência, entretanto, apresentou magnitude inferior às taxas de crescimento referente aos professores empossados, ficando em $1 \%$ ao mês no modelo estimado para o primeiro desenho avaliativo e $1,7 \%$ para o segundo desenho.

Um comportamento semelhante (de crescimento linear mensal) não parece ocorrer para os movimentos docentes referentes à chegada de professores transferidos de outras escolas (Tabela 2). Os coeficientes da variável tempo, neste caso, apontam um quadro de estabilidade, com variações médias mensais com magnitudes inferiores a 1\%. Além disso, os sentidos da associação com a variável dependente (número de professores que chegam transferidos) foram contrários nos modelos ajustados para os diferentes desenhos avaliativos e, para o segundo desenho, o coeficiente não foi estatisticamente significativo.

Outra variável temporal que se mostrou relevante foi o número de professores que haviam saído de uma determinada escola nos dois meses anteriores àquele observado. Esta representa uma demanda pretérita por profissionais, no caso das entradas de professores (por posse ou transferência) ou um efeito histórico contextual, no caso dos registros de saídas de professores. De fato, uma maior saída de professores em meses anteriores se mostrou associada com o aumento da movimentação docente nos meses posteriores, tanto para as entradas, quanto para as saídas de profissionais de educação. Esta variável foi especialmente relevante para explicar a chegada de professores nas escolas, principalmente por transferências internas da própria rede. Por outro lado, os coeficientes dos modelos correspondentes ao segundo desenho avaliativo foram sempre superiores, indicando que, de modo geral, a saída e a rotatividade de professores são relativamente mais elevadas nos territórios que receberam UPPs.

Pensando em efeitos territoriais, interessou verificar o impacto sobre os indicadores de mobilidade docente da proximidade ou do pertencimento das escolas em relação às áreas consideradas favelas. Para tanto, foi computada uma variável que indicava unidades 
educacionais dentro de setores censitários definidos no Censo 2010 (pelo IBGE, em parceria com o Instituto Pereira Passos), como aglomerados subnormais, bem como unidades dentro de uma distância de 100 metros de setores censitários considerados favelas. A presença desta variável é importante, sobretudo no primeiro desenho avaliativo, pois permite separar o efeito da entrada das UPPs do efeito territorial correspondente às favelas.

Como o efeito desta variável poderia ser endógeno à presença das UPPs, esperava-se que resultados mais consistentes pudessem ser vislumbrados nos modelos ajustados a partir do primeiro desenho avaliativo, que possui mais unidades em territórios fora de favelas. No segundo desenho, por outro lado, há uma maior superposição entre favelas e circunscrições das UPPs, e poucas unidades simultaneamente fora dos raios de proximidade considerados para favelas e UPPs - com, respectivamente, 100 e 250 metros. De fato, foi o que ocorreu. Para os três indicadores de mobilidade docente, os efeitos territoriais atribuídos à localização das escolas em territórios de favela foram significativos nos primeiro desenho e não significativos no segundo desenho. Além disso, no segundo desenho, perdeu-se a capacidade de distinguir os efeitos de proximidade dos territórios vizinhos das circunscrições das UPPs, que, para esta amostra mais reduzida, passaram a não ser significativamente diferentes das escolas completamente fora das áreas de UPP.

Como pode ser visto na Tabela 2, o fato de uma instituição de ensino estar localizada em território de favela, ou de estar próximo a uma destas localidades, reduz a capacidade das escolas de atrair professores por meio de transferências internas da própria rede municipal. Os coeficientes estimados para o primeiro desenho avaliativo apontam que esta redução chega a $41 \%$ para as escolas localizadas dentro dos territórios das favelas, sendo de $16 \%$ para escolas próximas a uma favela, em comparação com estabelecimentos de ensino localizados a mais de 100 metros de qualquer favela.

Por sua vez, registrou-se uma associação positiva entre a favela e a entrada de professores recém-empossados nas escolas; e uma associação negativa, ou inversamente proporcional, com o número de saídas de professores. Em outras palavras, a proximidade com a favela, segundo os modelos estimados, eleva o número de posses e reduz o número médio de saídas de professores transferidos para outras escolas. Estes são resultados que contrariam as expectativas iniciais. No caso das posses, este resultado pode traduzir um maior déficit de mão-de-obra docente nas escolas das favelas. Deste modo, este resultado poderia refletir o 
fato de que chegam mais professores nestas escolas justamente porque é nelas que existem mais vagas, que faltam mais professores. Por outro lado, as vagas disponíveis para os professores novatos, estariam sempre localizadas em áreas onde outros professores não querem estar: áreas de difícil acesso, mais distantes ou vistas como perigosas. No que concerne à menor saída de professores das escolas nos territórios das favelas, algumas hipóteses explicativas incluem a identificação dos docentes com estas escolas ou impedimentos institucionais (permissão das CREs ou das diretorias para a saída da escola). De todo modo, novos estudos serão necessários.

Os efeitos das UPPs e da proximidade em relação às circunscrições destas unidades registraram configurações distintas para os três indicadores analisados. No que tange às posses (Tabela 1), a presença ou proximidade de uma UPP parece estar relacionada a um aumento no número médio de novos professores que chegam às escolas. Em relação aos estabelecimentos de ensino completamente fora das áreas com UPP, os coeficientes foram maiores tanto para as escolas presentes nas circunscrições das unidades pacificadoras (39\% no modelo do primeiro desenho avaliativo e $34 \%$ para o segundo desenho), quanto nos territórios vizinhos a estas circunscrições - $36 \%$ e $29 \%$ para os modelos estimados para o primeiro e segundo desenhos, respectivamente. Assim, sugere-se que quanto mais próxima está a instituição de ensino do território da UPP, maior é o efeito sobre esta variável. Estes resultados foram bem pronunciados no modelo estatístico ajustado para o primeiro desenho, para toda a cidade, e se mostraram mais modestos nas análises que se restringiram às áreas de UPP, ao ponto que a proximidade em relação à UPP (buffer de 250 metros da circunscrição) deixou de ser estatisticamente significativa, nas análises do segundo desenho. Estes resultados podem representar, por um lado, uma redução do estigma proveniente da associação entre favela e violência; podendo ainda responder a um cálculo racional dos professores recémchegados durante a escolha da escola em que irão iniciar suas atividades docentes. Entre escolas de difícil acesso e localizadas em favelas, estar em área de UPP poderia configurar um diferencial para determinadas escolas. Por outro lado, este resultado pode representar um maior investimento governamental nas áreas já atendidas pelo projeto.

No que se refere às saídas de professores (Tabela 3), os resultados dos modelos apontaram efeitos significativos mais com sinais invertidos entre as análises dos dois desenhos avaliativos. Para o primeiro desenho, mais geral, as UPPs parecem estar associadas, 
contrariando o que se esperava, ao aumento das transferências de professores para outras escolas - à saída de professores. Já os coeficientes do modelo estimado para o segundo desenho avaliativo, as UPPs estão relacionadas à diminuição das saídas dos docentes. Para o número de entradas de professores nas escolas, por meio de transferências, a presença das UPPs não foi estatisticamente significativa em nenhum dos dois desenhos avaliativos.

\section{Considerações Finais}

Este artigo discorreu sobre possibilidades teóricas e empíricas de trabalhar a relação entre violência e oportunidades escolares, a partir dos impactos educacionais promovidos pela redução dos conflitos armados resultante da intervenção das UPPs. Propôs-se um desenho avaliativo baseado em Séries Temporais Múltiplas (Campbell \& Stanley, 1963).

O desenho proposto foi colocado em prática utilizando registros administrativos com informações sobre movimentos docentes, cedidos pela Secretaria Municipal de Educação do Rio de Janeiro (SME). Os registros considerados abarcaram o período de janeiro de 2006 a dezembro de 2011. Foi realizada uma análise exploratória, na qual foram ajustados modelos lineares generalizados mistos, que consideram nas estimativas a estrutura hierárquica dos dados (mensurações repetidas, por mês, para as mesmas escolas). Estes modelos foram ajustados para duas amostras diferentes: uma que considerou todas as escolas da rede municipal carioca e outra que considerou apenas as escolas nas circunscrições das UPPs ou dentro de uma distância de 250 metros destas. Buscou-se verificar impactos das UPPs sobre a capacidade das escolas de manter e atrair profissionais, mais especificamente, docentes.

Foram três os indicadores de movimentação docente observados: os números de professores que entravam na escola, (a) recém-empossados ou; (b) por meio de transferências internas de outras escolas; e também (c) o número de professores que saíam das escolas através de transferências dentro da própria rede municipal. Os resultados para as posses apontaram aumento, nas áreas de UPPs, do número médio de docentes novos que chegavam às escolas, mas os efeitos sobre as entradas por transferência interna não foram significativos.

Os modelos estimados para as saídas das escolas por transferência foram, a princípio, inconclusivos. Os coeficientes para as saídas de professores das escolas foram contrários nos dois modelos estatísticos estimados, a partir das duas diferentes amostras. No modelo pertinente ao primeiro desenho avaliativo, com todas as escolas municipais, os resultados da 
análise exploratória apontaram que a presença das UPPs estava associada a um aumento da saída de professores, enquanto a análise com uma amostra de escolas, restrita apenas aos territórios em que foram implantadas UPPs, apontou uma associação negativa, onde a presença de UPPs estaria relacionada à diminuição da saída de professores transferidos para outras escolas. Estes resultados discrepantes entre os modelos estimados para as duas amostras trazem consigo uma discussão sobre a definição dos grupos de controle mais adequados para se testar os impactos educacionais das UPPs. Futuros trabalhos deverão considerar esta questão com mais atenção e podem lançar mão de técnicas de pareamento (matching) e escores de propensidade (propensity score) para definição de grupos de controle.

Este artigo configura apenas o início de um trabalho, e muitas outras análises (quantitativas e qualitativas) serão ainda realizadas. As próximas análises devem incorporar aos modelos novas variáveis de controle pertinentes às escolas, que possam estar potencialmente associadas aos movimentos docentes. Devem ser testados efeitos cumulativos das UPPs no tempo, considerando diversos cenários de implementação do projeto. Além disso, novos indicadores ajudarão a testar hipóteses alternativas, como políticas específicas de recrutamento e projetos como o programa "Escolas do Amanhã", iniciado quase que paralelamente às UPPs.

\section{Referências Bibliográficas:}

ALVES, José Cláudio Souza. "Milícias: Mudanças na Economia Política do Crime no Rio de Janeiro". in: JUSTIÇA GLOBAL (org.). Segurança, tráfico e milícia no Rio de Janeiro. Rio de Janeiro: Fundação Heinrich Böll, 2008.

BURGOS, Marcelo Baumann Burgos. "Dos parques proletários ao Favela-Bairro: as políticas públicas nas favelas do Rio de Janeiro". In: ALVITO, M. e ZALUAR, A. (orgs.). Um século de favela, Rio de Janeiro: Fundação Getúlio Vargas, 1998.

CAMPBELL, Donald Thomas; STANLEY, Julian Cecil. "Experimental and quasiexperimental designs of research". in: Gage, N.L. Handbook of research on teaching. Chicago: Rand McNally, 1963.

CANO, Ignacio. Introdução à avaliação de programas sociais. Rio de Janeiro: Ed. FGV, 2002.

CANO, Ignacio. “Avaliação de Programas de Intervenção em Violência, Criminalidade e Segurança Pública”. In. BRITO, D.C.; BARP, W.J. (org.) Violência e Controle Social. Reflexões sobre Políticas de Segurança Pública. Edufpa. 2005. 
CANO, Ignacio; IOOT Carolina. "Seis por meia dúzia?: um estudo Exploratório do fenômeno das Chamadas'milícias' no Rio de Janeiro". in: JUSTIÇA GLOBAL(org.). Segurança, tráfico e milícia no Rio de Janeiro. Rio de Janeiro: Fundação Heinrich Böll, 2008.

CANO, Ignacio; RIBEIRO, Eduardo. Homicídios no Rio de Janeiro e no Brasil: Dados, políticas públicas e perspectivas. In: M. V. G. D. CRUZ \& E. C. BATITICCI (Org.). Homicídios no Brasil. Rio de Janeiro: FGV editora, 2007, p.28.

CANO, Ignacio; SENTO-SÉ, João Trajano; RIBEIRO, Eduardo, SOUZA, Fernanda Fernandes $\mathrm{O}$ impacto da violência no Rio de Janeiro. (Relatório de pesquisa). - Rio de Janeiro: Laboratório de Análise de Violência, 2004.

CANO, Ignacio; BORGES, Doriam; RIBEIRO, Eduardo. 'Os donos do morro': uma avaliação exploratória do impacto das unidades de polícia pacificadora (UPPs) no Rio de Janeiro. São Paulo: Fórum Brasileiro de Segurança Pública, 2012 (mimeo).

DOWDNEY, Luke. Crianças do tráfico: um estudo de caso de crianças em violência armada organizada no Rio de Janeiro. Rio de Janeiro: 7 Letras, 2003.

IBPS. Pesquisa sobre a percepção acerca das Unidades de Polícia Pacificadora. Pesquisa PR 004-10-UPP-25.01. Relatório de Pesquisa. Janeiro de 2010 (mimeo).

KOSLINSKI, Mariane Campelo; LASMAR, Cristiane; ALVES, Fátima. "Observatório Educação e Cidade: algumas hipóteses sobre a relação entre território e oportunidades educacionais". Rio de Janeiro. Revista e-metropolis, n.8, 2012. p. 8-20.

LEEDS, Elizabeth. "Cocaína e poderes paralelos na periferia urbana brasileira: ameaças à democratização em nível local”. ALVITO, M. e ZALUAR, A. (orgs.). Um século de favela, Rio de Janeiro: Fundação Getúlio Vargas, 1998.

MAFRA, Clara. "Drogas e Símbolos: redes de solidariedade em contextos de violência". ALVITO, M. e ZALUAR, A. (orgs.). Um século de favela, Rio de Janeiro: Fundação Getúlio Vargas, 1998.

MICHAUD, Yves. A violência . São Paulo: Ática, 1989. (Fundamentos)

MISSE, Michel. "O movimento: a constituição e reprodução de redes do mercado informal ilegal de drogas a varejo no Rio de Janeiro e seus efeitos de violência". in. Drogas e Modernidade: faces de um tema proscrito. BAPTISTA M.; CRUZ M.S; MATIAS R. (orgs.). - Rio de Janeiro: EdUERJ, 2003. 2.v.

PAIVA, Angela Randolpho, BURGOS, Marcelo Baumann Burgos. A Escola e a Favela. Rio de Janeiro, PUC-Rio, 2009.

RIBEIRO, Luiz Cesar de Queiroz; KOSLINSKI, Mariane Campelo. "Fronteiras urbanas e oportunidades educacionais: o caso do município do Rio de Janeiro". in. RIBEIRO, L.C.Q., KOSLINSKI, M.C, ALVES Fátima.; LASMAR C. (orgs.). Desigualdades 
urbanas, desigualdades escolares. Rio de Janeiro: Letra Capital: Observatório das Metrópoles: IPPUR/UFRJ, 2010. (Metrópoles).

RIBEIRO, Luiz Cesar de Queiroz; KAZTMAN, Ruben. (ed.). A cidade contra a Escola: Segregação urbana e desigualdades educacionais em grandes cidades da América Latina. Rio de Janeiro: Letra Capital, 2008.

SILVA, Jailson de Souza e; FERNANDES, Fernando Lannes; BRAGA, Raquel Willadino. "Grupos criminosos armados com domínio de território Reflexões sobre a territorialidade do crime na Região Metropolitana do Rio de Janeiro". in JUSTIÇA GLOBAL (ORG.). Segurança, tráfico e milícia no Rio de Janeiro. Rio de Janeiro: Fundação Heinrich Böll, 2008.

SHADISH, William. R., COOK, Thomas D.; CAMPBELL, Donald Thomas. Experimental and Quasi-experimental designs for generalized causal inference. Boston: HoughtonMifflin, 2002.

SKOLNICK, Jerome Herbert, BAILEY David. Policiamento Comunitário. São Paulo: Editora EDUSP, 2002.

SOARES, Luiz Eduardo. "A Política Nacional de Segurança Pública: histórico, dilemas e perspectivas". In: Estudos avançados. [online]. 2007, vol.21, n.61, pp. 77-97.

\title{
IMPACTS OF THE PACIFYING POLICE UNITS ON EDUCATION: EXPLORING THE EFFECTS ON TEACHER TURNOVER
}

\begin{abstract}
As of the year 2008, the government of the state of Rio de Janeiro has initiated a set of public interventions called Pacifying Police Unit (PPU). They are permanent occupations of territories previously ruled by drug traffic dealers with the installation of local police units. It ideally followed by implementation of social projects and public services. The PPUs are an alternative to the traditional paradigm of drug traffic combat policy and even though they coexist with the old model (military and repressive), they should lead, indirectly, to changes in different aspects of city life. In this sense, this paper will discuss about the possible impacts of PPU in the educational outcomes in the target areas, and it will explore changes in the teacher flow and turnover rates at municipal public schools.
\end{abstract}


KEYWORDS: Evaluation of Public Policies; Impacts of Violence; Education. 